\title{
Incentive and Restrictive Mechanism of Knowledge Sharing in Basic Education Groups
}

\author{
https://doi.org/10.3991/ijet.v16i03.20467 \\ Yafei Wang \\ North China University of Technology, Beijing, China \\ faye791108@163.com
}

\begin{abstract}
As a kind of strategic alliance, basic education groups rely on the knowledge sharing and coordination among group members, in addition to the sharing of tangible assets, to promote education fairness and improve education quality. This paper aims to incentivize and restrict the knowledge sharing among group members. Firstly, the authors analyzed the economies of scale, economies of scope, and the economies of connection brought by the knowledge sharing among group members, and summarized the problems and challenges faced by knowledge sharing. Then, the evolution mechanism of the knowledge sharing among group members was studied from the perspective of game theory, and the suggestions were proposed to improve the incentive and restrictive mechanism of the knowledge sharing among group members. The research results shed a new light on the knowledge sharing in basic education groups.
\end{abstract}

Keywords-Basic education group, knowledge sharing, game, incentive and restrictive mechanism

\section{Introduction}

The so-called strategic alliance is a long-term or short-term cooperative relationship formed by two or more relatively independent organizations through agreements or other forms in the purpose of achieving their respective strategic goals; and the alliance partners would maintain a cooperative and competitive relationship [1]. In a strategic alliance, members in the alliance exchange knowledge with each other, a knowledge resource shared by one member would be transmitted to the entire group through such exchanges, forming synergistic effects and innovation diffusion, thereby enhancing the overall strength of the group. A basic education group is a collection of two or more schools, essentially, it is also a strategic alliance. Up to now, there are many studies on the internal knowledge sharing of strategic alliances in business areas such as corporate group subsidiaries and project teams; however, in terms of the internal knowledge sharing in non-profit organizations such as basic education groups, the research is insufficient, and there's a necessity to explore the incentive and restrictive mechanism of knowledge sharing among different group members. 
In recent years, people have a growing interest in the process of team success (such as an enterprise), and research has been conducted to figure out why some teams are more successful than other teams [2]. For enterprises, their competitiveness mainly comes from intangible assets rather than tangible assets, such as knowledge sharing [3]. As one of the most important content in knowledge management, knowledge sharing is a hot topic in the field of knowledge management and it mainly focuses on three key aspects: individuals, organizations, and technologies [4].

A group of geographically or organizationally dispersed colleagues can make efforts towards a common goal with various technologies as the intermediaries [5]. Inside a strategic alliance, group members use information and communication technologies for communication and cooperation [6].

In the economic field, knowledge is the core strategic resource of an enterprise. Compared with the traditional innovation method that an enterprise makes innovations in a closed state, the open-state innovation method participated by multiple enterprises has the advantages of risk-sharing, win-win situation, and continuous innovation, etc. [7]. The knowledge sharing behavior based on enterprise clusters is an important way for enterprises to bridge the knowledge gap and achieve knowledge innovation [3]. At the same time, how to realize knowledge sharing is one of the biggest challenges for innovation management [8]. As market demands are becoming increasingly complex and diversified, more enterprises in the cluster network adopt knowledge sharing and other collaborative methods to increase their benefits [9]. Kong et al. [10] analyzed the dynamic evolution of the knowledge sharing behavior of enterprises in the cluster network based on game theory, and discussed the factors affecting the evolution trajectory.

Knowledge sharing is a valuable resource, its value depends on its quality [11]; knowledge sharing may fail due to many reasons, such as the lack of support from the organization or insufficient training [12].

Many scholars have conducted research on the influencing factors of knowledge sharing among different groups, including the group's trust, the knowledge sharing atmosphere [13], and the ethnic culture [14]. Some scholars took different type strategic alliances as examples to study the mechanism of internal knowledge sharing, and found that there're significant positive correlations among collaborative innovation activities, knowledge sharing, collaborative innovation abilities and corporate innovation performance [15]; and they also analyzed the mechanism and barriers of knowledge sharing from four levels: inside an organization, inside a project, between projects, and outside a project [16]. Research on the key factors of knowledge sharing practices in the oil and gas industry shows that knowledge sharing has a positive impact on the performance of an organization [17]. Among the subsidiary companies of an enterprise group, the highly-collaborative knowledge sharing can improve the global performance of the subsidiary companies of the group [18]. The effectiveness of internal knowledge sharing in a multinational enterprise has a significant impact on the performance of the subsidiaries of the multinational enterprise [19]. The paternalistic-style leadership of Chinese companies can promote interpersonal relationships and long-term relationships with alliance partners, which may increase the opportunities of sharing knowledge with external partners [20]. 
In summary, above studies mostly concerned about the influencing factors and realization mechanism of the internal knowledge sharing of economic entities such as enterprise groups. Although some took education organizations as subjects, such as Li's study [21] had pointed out that the knowledge sharing of university alliances requires a cross-cultural environment, still there's very few researches paying attention to the internal knowledge sharing of basic education groups. As a kind of strategic alliance, a basic education group's success in promoting education fairness and improving education quality not only relies on the sharing of tangible assets of the group members, but also the knowledge sharing and coordination among these members.

This paper analyzes the economies of scale, economies of scope, and the economies of connection of the knowledge sharing among group members, and points out the problems and challenges faced by knowledge sharing; from the perspective of game theory, the paper studies the evolution mechanism of knowledge sharing among group members, and proposes a few suggestions to improve the incentive and restrictive mechanism of the knowledge sharing among group members.

\section{Benefits of Knowledge Sharing in Basic Education Groups}

In recent years, with the development of economy and the advancement of society, people have a growing requirement for high-quality education and an urgent appeal for educational fairness. In this context, schools have united to become basic education groups which spring up like mushrooms around the country, such educational reform forms have been explored and attempted in various places and become an important educational reform and innovation measure for the basic education system in China. Basic education groups are often composed of multiple member schools with different situations, each has their respective knowledge systems, teaching facilities, and faculty teams. Through knowledge sharing and coordination mechanism, knowledge transfer and sharing could be realized within the basic education groups, forming scale economies effect, scope economies effect, and connection economies effect.

\subsection{The scale economies effect of knowledge sharing of basic education groups}

For basic education groups, the effect of scale economies in knowledge sharing is manifested in the following aspects: first, as the number of member schools in the education group increases, the scale of the group grows, the knowledge can be used repeatedly in member schools and it won't be consumed due to such use. In the sharing process, as the usage count of the knowledge increases, the average cost decreases continuously. Second, the collaborative cost of knowledge sharing within the group, such as the input cost of data processing equipment, teaching software, and management resources, will decrease as the usage of knowledge increases. Third, knowledge has the unique advantage of increasing marginal benefits. Under the effect of the 
knowledge sharing mechanism of the group, the marginal benefits will expand constantly, and accumulate, refine and appreciate during continuous use.

\subsection{The scope economies effect of knowledge sharing of basic education groups}

In a basic education group, there are many member schools; the teaching emphasis and requirements of these schools are different, therefore, it's necessary and possible to allocate various kinds of knowledge resources, namely multiple "product lines"; due to the convenience created by the collaborative mechanism, cost for multiple members to use multiple knowledge resources is lower than the cost of a single knowledge resource. For example, with the support of the online course platforms of the education group, member schools can develop and promote various courses on these platforms; compared with developing and promoting a single course, costs such as communication and transactions can be reduced significantly, and thus realizing the effect of the scope economies.

\subsection{The connection economies effect of knowledge sharing of basic education groups}

The important characteristics of the connection economies include not only the low cost caused by the input common production factors, but also the multiplier effect produced by the output combination of multiple organizations and entities [22]. For the basic education groups, under the effects of knowledge sharing and collaboration mechanism, in the process of knowledge sharing and transfer, member schools integrate different knowledge and create new knowledge, and thereby increasing the values.

\section{Necessity and Challenges of Knowledge Sharing in Basic Education Groups}

According to above analysis, knowledge sharing has the scale economies effect, the scope economies effect, and the connection economies effect within the basic education groups, however, in practice, it's of great necessity and urgency for basic education groups to achieve knowledge sharing within the organization, and it also faces many challenges [23].

First, insufficient knowledge resources: In China, basic education groups mostly adopt the model of " 1 advantaged + n disadvantaged", the knowledge resource owned by the dominant school acts as the important support of the group, however within the education group, the total amount of knowledge resources is always insufficient, including manpower (faculties), teaching platforms (such as online course platform), books and materials, and institutional and cultural resources, etc.

Second, scarce high-quality knowledge resources: There are obvious differences in the scale, competence and development level of the member schools in the educa- 
tion group. Excellent teachers are scarce, advanced knowledge dissemination equipment is scarce, and efficient operation system is scarce as well. The scarcity of resources makes the competition to win high-quality resources inevitable, therefore, how to design an incentive and restrictive mechanism for knowledge sharing is crucial.

Third, lack of external pressure for knowledge sharing: There are multiple resource supply channels of education groups, including government input, market support, and the accumulation of group members, which means that the allocation of resources within the education group is the result of the group game under the multisubject interest structure. In this structure, the government plays the dominant role in education resource (including knowledge resource) allocation, however in reality, the government usually acts as the game rule maker, the judge or the mediator in the resource allocation process; it rarely promotes or participates in the resource game. The absence of government regulation makes the resource game behaviors of different interest parties lose an important constraint. To maximize their own interests, their gaming behaviors might be random.

Fourth, lack of internal motivation for knowledge sharing: In China, a few basic education groups adopt the joint mode of " $1+X$ ", the legal person's dominant position is not significant, which makes it difficult to build a powerful internal governance structure. Each member school has its own interest orientation and goals. The leading school is not motivated to share its resources with other member schools; the organizational form is loose, the resource allocation efficiency is low, and the group lacks the binding force.

Fifth, lack of incentive and restrictive mechanism for knowledge sharing: An effective mechanism can promote the sharing of knowledge resources within the education groups. However, for current education groups in China, there are problems in three aspects: first, in terms of resource input, the resource budgeting and resource management have not been effectively integrated; second, in terms of resource coordination, the group members are relatively independent from each other, and the effect of resource sharing is not good; third, in terms of faculty construction, the flow of teacher resource is insufficient, the teacher-student ratio is inappropriate, resulting in the phenomenon of "resource dilution" in leading schools.

\section{Game Analysis of Knowledge Sharing Strategies of Basic Education Groups}

The knowledge interaction, sharing and learning among member schools in basic education groups are dynamic; during the establishment and operation process of the education groups, a large amount of knowledge and skills are generated and accumulated, and these are precious resources for all member schools. In the process of knowledge resource optimization and value increment, the entire group directly benefits from it. However, the prosperity of group knowledge requires continuous knowledge creation and contribution from member schools. If member schools overprotect their knowledge, it'll inhibit the transfer and sharing of knowledge within the 
group, then, knowledge resource islands and deserts would form within the group, curbing the effects of resources and lowering the overall inefficiency of the group.

From the perspective of system theory, basic education group is a graduallyevolving knowledge sharing system; therefore, this paper applies the idea of evolutionary game theory to discuss the game process and strategy choice of knowledge sharing among group members from the perspective of dynamic game.

Evolutionary game theory is a theory that combines game theory analysis and dynamic evolution process analysis. Unlike the traditional game theory which assumes that participants are completely rational, the evolutionary game theory does not emphasize that participants are completely rational and it does not know all the details of the game, including the participants' preferences for the outcome of the game. The evolutionary game theory assumes that the participants are randomly selected, they play the game repeatedly according to the laws and methods of biology or society, and they make diachronic evolutionary choices in the overall distribution of behaviors. Through learning and imitation, participants keep trying constantly, and then choose the evolutionary game strategies. After long-term imitation and improvement, all participants would tend to a stable strategy, which is called the "Evolutionary Stable Strategy" (ESS) [24].

Drawing lessons from Liu's [25] game analysis model when studying the knowledge sharing of corporate strategic alliances, it is assumed that the two sides of the game are two randomly selected member schools of the basic education group, the rationality of both parties in the game satisfies the limited rationality assumption; the strategic choice of the two parties is sharing the knowledge or not sharing the knowledge, this indicates that the game is an asymmetric evolutionary game, and the payoff matrix of both parties is shown in Table 1 .

Table 1. Payoff matrix of both parties of the game in a basic education group

\begin{tabular}{|c|c|c|c|}
\hline & \multicolumn{2}{|c|}{ Member school 2} \\
\hline & & Share knowledge & Not share knowledge \\
\hline \multirow{2}{*}{$\begin{array}{l}\text { Member } \\
\text { school } 1\end{array}$} & Share knowledge & $\pi_{1}+r_{1}-1_{1} a_{1}, \pi_{2}+r_{2} a_{1}-l_{2} a_{2}$ & $\pi_{1}-1_{1} \mathrm{a}_{1}, \pi_{2}$ \\
\hline & Not share knowledge & $\pi_{1}, \pi_{2}-\mathrm{l}_{2} \mathrm{a}_{2}$ & $\pi_{1}, \pi_{2}$ \\
\hline
\end{tabular}

In the above payoff matrix, $\pi \mathrm{i}(\mathrm{i}=1,2)$ represents the normal earnings obtained when the two member schools choose the strategy of not sharing the knowledge; ai is the knowledge level coefficient, it represents the knowledge level of the member schools; ri is the earnings coefficient, it represents the ability of a member school to produce earnings after it absorbed and transformed the knowledge shared by other member schools; $r_{1} a_{2}$ and $r_{2} a_{1}$ are the excess earnings obtained when the two member schools choose the strategy of sharing the knowledge; li is the risk coefficient, it represents the risk level of member school $i$ when it chooses the strategy of sharing the knowledge in the comprehensive environment of the basic education group; liai is the initial cost paid by school $i$ when it chooses the strategy of sharing the knowledge. Under normal conditions, when both member schools choose the strategy of sharing the knowledge, the obtained excess earning is greater than the initial cost, namely $\mathrm{r}_{1} \mathrm{a}_{2}>\mathrm{l}_{1} \mathrm{a}_{1}, \mathrm{r}_{2} \mathrm{a}_{1}>\mathrm{l}_{2} \mathrm{a}_{2}$. 
Assume that the probability of member school 1 choosing the sharing strategy is $\mathrm{x}$, then the probability of member school 1 choosing the not-sharing strategy is $1-x$; also, assume the probability of member school 2 choosing the sharing strategy is $y$, then the probability of member school 2 choosing the not-sharing strategy is $1-y$; then, when member school 1 chooses the sharing strategy, the earning is:

$u_{1}^{\prime}=\mathrm{y}\left(\pi_{1}+\mathrm{r}_{1} \mathrm{a}_{2}-\mathrm{l}_{1} \mathrm{a}_{1}\right)+(1-\mathrm{y})\left(\pi_{1}-\mathrm{l}_{1} \mathrm{a}_{1}\right)$

When member school 1 chooses the not-sharing strategy, the earning is:

$u_{1}^{n}=\mathrm{y} \pi_{1}+(1-\mathrm{y}) \pi_{1}$

The average earning of member school 1 is:

$\overline{u_{1}}=\mathrm{x} u_{1}^{n}+(1-\mathrm{x}) u_{1}^{n}=(1-\mathrm{x})\left(\mathrm{r}_{1} \mathrm{a}_{2} \mathrm{y}-\mathrm{l}_{1} \mathrm{a}_{1}\right)$

Similarly, the average earning of member school 2 is:

$\overline{u_{2}}=(1-\mathrm{y})\left(\mathrm{r}_{2} \mathrm{a}_{1} \mathrm{x}-\mathrm{l}_{2} \mathrm{a}_{2}\right)$

Construct the replicator dynamics equations of the group member schools respectively:

$$
\begin{aligned}
& \frac{d x}{d t}=\mathrm{x}(1-\mathrm{x})\left(\mathrm{r}_{1} \mathrm{a}_{2} \mathrm{y}-\mathrm{l}_{1} \mathrm{a}_{1}\right) \\
& \frac{d y}{d t}=\mathrm{y}(1-\mathrm{y})\left(\mathrm{r}_{2} \mathrm{a}_{1}-\mathrm{l}_{2} \mathrm{a}_{2}\right)
\end{aligned}
$$

Let Equations (1) and (2) equal to zero, then for the knowledge sharing system of the basic education group constituted by these two member schools, 5 evolutionary equilibrium solutions could be obtained, namely $(0,0),(0,1),(1,0),(1,1),\left(l_{2} \mathrm{a}_{2} / \mathrm{r}_{2} \mathrm{a}_{1}\right.$, $\left.l_{1} a_{1} / r_{1} a_{2}\right)$. The eigenmatrix of the above evolution equations is:

$$
A=\left[\begin{array}{cc}
(1-2 x)\left(r_{1} a_{2} y-l_{1} a_{1}\right) & x(1-x) r_{1} a_{2} \\
y(1-y) r_{2} a_{1} & (1-2 y)\left(r_{2} a_{1} x-l_{2} a_{2}\right)
\end{array}\right]
$$

According to the principle of ordinary differential, stability analysis was carried out based on these 5 equilibrium points. When $r_{1} a_{2}>l_{1} a_{1}$ and $r_{2} a_{1}>l_{2} a_{2}$, point $(0,0)(1$, $1)$ is an ESS point, point $(0,0)(1,1)$ is an unstable point, and point $\left(\mathrm{l}_{2} \mathrm{a}_{2} / \mathrm{r}_{2} \mathrm{a}_{1}, \mathrm{l}_{1}\right.$, $\left.\mathrm{a}_{1} / \mathrm{r}_{1} \mathrm{a}_{2}\right)$ is a saddle point.

According to the analysis of the evolutionary game model, the long-term equilibrium structure of the evolutionary game of the basic education group knowledge sharing system may be complete knowledge sharing $(1,1)$ or complete knowledge nonsharing $(0,0)$. This result is closely related to the payoff matrix and initial state of the evolutionary game, therefore, in the evolutionary game process, the initial values and changing trends of the parameters that constitute the revenue functions of the two game parties will drive the evolutionary system to converge to different equilibrium points.

The following figure describes the dynamic process of the game between two member schools. The broken lines connected by unstable equilibrium points A, B and 
saddle point $\mathrm{D}$ are the critical lines for the knowledge sharing system to converge to different status. In the ADBC part on the upper right of the broken lines, the system converges to the mode in which the two member schools choose to share the knowledge; while in the ADBO part at the lower right of the broken lines, the system converges to the mode in which the two member schools choose to not share the knowledge.

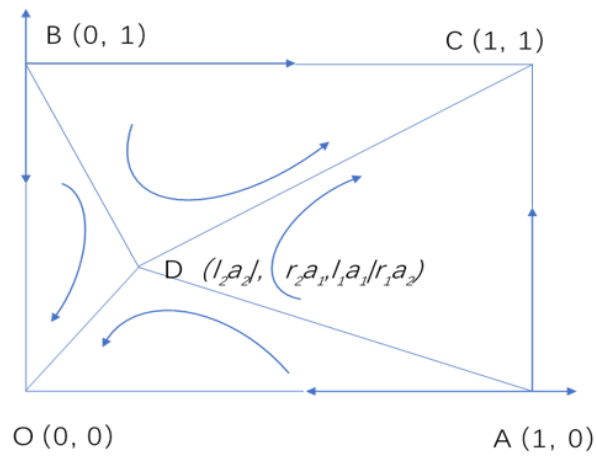

Fig. 1. Dynamic evolution of the knowledge sharing system of basic education groups

\section{$5 \quad$ Influencing Factors of Knowledge Sharing Strategy of Basic Education Groups}

The above-mentioned evolutionary game analysis of the knowledge sharing strategies of basic education groups is a simplified model, but the principles it revealed are universal. According to above analysis, the strategy choice of member schools is mainly determined by the initial parameters of the knowledge sharing system, that is, with the increase of revenue coefficient ri and the decrease of risk coefficient li, the knowledge level gap ai between group members narrows, the saddle point $\mathrm{D}$ constantly approaches the origin point $\mathrm{O}$, the possibility of the system converging at point $\mathrm{C}$ increases, and the possibility of member schools choosing the knowledge sharing strategy increases as well. Therefore, the influencing factors of the knowledge sharing strategies of basic education groups can be summarized as: knowledge sharing benefits, knowledge sharing risks and knowledge sharing difficulties.

\subsection{Knowledge sharing benefits}

Knowledge sharing benefits are the newly added values brought by knowledge sharing to all parties in the group. The benefits and rewards that a member school obtains from knowledge sharing are related to the value of knowledge contributed by the school itself, the value of knowledge contributed by other member schools, and the ease of knowledge sharing within the group. Moreover, the value of knowledge contributed by member schools is related to factors such as the schools' knowledge 
level and knowledge absorption capacity, etc. If a member school thinks that the knowledge shared by other member schools is not of high value, or it is less valued than the knowledge shared by itself, then, this member school would consider itself at a loss, in the long run, without enough sufficient incentives, the school is not motivated to continue to share its knowledge, or it shares knowledge purely due to pressure, and it might have reservations or "work without effort". In addition, if a member school thinks it's hard to judge the value of the shared knowledge, or the value is not easily evaluated, then its enthusiasm for knowledge sharing will be reduced, and this is not good for the sharing of tacit knowledge, by "tacit knowledge" we mean the knowledge we know but can hardly tell or explain. The knowledge sharing technology and conditions in the group, such as whether there's efficient knowledge sharing platform, have an important impact on the sharing and creation of knowledge after the school joins the group.

\subsection{Knowledge sharing risks}

Knowledge sharing risks are the possibility of value loss caused by knowledge sharing to the group member schools. Knowledge sharing might bring some negative effects, and the knowledge sharing risks are mostly related to the sharing of tacit knowledge. Because of the comprehensive strength ranking competition among member schools, the management of member schools and the teachers generally have competitive relationships in terms of economic benefits and social interests. Out of the consideration of their own interests, they are afraid of the loss of their own core competence and interests once the knowledge they mastered has been transferred completely, therefore, they are not willing to share their knowledge [26].

\subsection{Knowledge sharing difficulties}

In a basic education group, the knowledge structures of different member schools are quite different. If there is no efficient knowledge sharing infrastructure, it'll take a lot of time and energy to organize, share and transfer the knowledge, the sharing party will lack the motivation and the receiving party will have great pressure, which will limit knowledge sharing and collaboration.

\section{Guarantee Mechanism for Knowledge Sharing of Basic Education Groups}

Above analysis of the influencing factors of knowledge sharing suggests that, to improve the effect of knowledge sharing, we need to start from the aspects of increasing knowledge sharing benefits of group member schools, lowering knowledge sharing risks, and reducing knowledge sharing difficulties. 


\subsection{Establish knowledge sharing systems in education groups}

In a basic education group, each member school has their respective interests and goals. The leading schools are worried about resource dilution therefore their motivation to share its own resources with other members is not strong, sometimes the advantaged schools "work without effort" when they are helping the disadvantaged schools. Also, even if a leading school is motivated to share its knowledge, there's still a "one size fits all" problem, that is, each member school would develop its own characteristics and advantages during the long-term school-running process, however the leading schools may ignore other member schools' development foundations, characteristics and potentials when they spoon-feed their knowledge resources to them, resulting in that the schools are all much of a muchness and lose their uniqueness. At the same time, due to the existence of costs, the resource sharing among member schools will not be realized automatically [27]. In the resource substitution game, different interest parties play the game constantly between the size of the costs and the success of resource substitution.

The value orientations of education groups and enterprise groups are fundamentally different. The non-profit nature of education groups determines that the market mechanism cannot regulate the allocation of education resources in the education groups, and administrative regulation is the main regulation method for the education resource allocation in education groups. Therefore, in the allocation process of education resources (including knowledge resources), the knowledge sharing system should be designed scientifically and reasonably so as to effectively measure and compare the degrees of demand of each resource demanders for the different resources, and clarify the rights, obligations, activities and behaviors of the knowledge resource allocation participants, thereby increasing the benefits of knowledge resource contributors and promoting the knowledge to flow to the schools that need it most [28].

\subsection{Establish incentive and restrictive mechanisms for knowledge sharing in education groups}

First, the incentive mechanism: Material and spiritual incentives can be used to motivate the knowledge sharers so as to efficiently and quickly achieve the goal of resource allocation equilibrium. In order to realize "ordered competition and cooperation" of different interest parties in the education groups, promote mutually beneficial cooperation and reduce vicious competition, it's necessary to establish an incentive mechanism that allows different interest parties to obtain material or spiritual incentives through cooperation.

Second, the restrictive mechanism: After member schools have signed the resource cooperation agreement and agreed to cooperate with other schools, once a school intends to breach the agreement due to its own interest, the education group can punish it according to the agreement, restrain the behaviors of its members within a certain range, and make them bear the consequences and losses caused by their behaviors. Moreover, the incentive mechanism and the restrictive mechanism should 
match with each other, so that for each reward, there's corresponding punishment [29].

\subsection{Unclog interest demand channels of knowledge sharing in education groups}

Interest is the driving force for all actions. In a basic education group, both the interests of the leading school and member schools are involved; only when the legitimate interests of the member schools have been guaranteed can the education group development smoothly, otherwise the members are just seemingly harmonious and will drift apart due to the lack of cohesion. Therefore, this paper proposes to establish a platform for member schools to make interest demands, unclog the interest demand channels for them, increase the benefits of all parties for sharing and transferring knowledge, allow and guide member schools to express their interest appeals, and make efforts to satisfy their legitimate interests. In terms of governance structure, basic education groups can learn from the operation mode of the enterprise groups, and establish the group board of directors, the group teacher representative conference, and the parent committee with all parties involved; then, for major events concerning the interests of each member school, the group board of directors and the group teacher representative conference can discuss and make decisions, and refer to the opinions of the parent committee.

\subsection{Establish a mechanism for evaluating and protecting group knowledge sharing achievements}

In order to motivate the initiative of group members for knowledge sharing and eliminate the different cognitions of the value of knowledge sharing among group members, education groups can recruit professionals and experts to evaluate the shared knowledge of group members; only when the tacit knowledge of group members has been evaluated and integrated into benefit distribution, and the member schools have realized that knowledge sharing is consistent with their own interests, can they be willing to share their knowledge. At the same time, it is necessary to formulate an intellectual property protection mechanism, clearly define the core knowledge and technology of member schools, enact internal rules and regulations to limit and punish behaviors that lead to the leakage and loss of core knowledge and technology, and formulate a compensation mechanism for transferring core knowledge resources among members in the group.

\subsection{Build knowledge sharing platforms to reduce costs of knowledge transfer}

Knowledge sharing technology is also an important factor affecting the value and efficiency of knowledge sharing in the group. Education groups need to strengthen the construction of knowledge sharing platforms. Especially in the new era of information technology, modern technologies such as the Internet, IoT, big data, and cloud computing should be applied comprehensively to promote knowledge sharing and trans- 
fer. The technical features of these technologies are digital, networked, intelligent, and multi-media; and their basic characteristics are open, shared, interactive, and collaborative. With the help of these techniques, excellent knowledge resources could be transmitted to each group members or even to the entire society at a low cost. In the field of higher education, a movement called Open Educational Resources (OER) has emerged in recent years, and universities such as Harvard, Yale, and MIT have provided online open courses ever since. Since 2020, due to the impact of the Covid19 epidemic, the Chinese education authorities have built various education resource sharing platforms and set up online courses, many of which depend on basic education groups and play an important role in knowledge sharing. In the next step, basic education groups should continue to enrich the content of the knowledge sharing platforms, reduce the costs of knowledge sharing, and improve the effectiveness of knowledge sharing.

\section{Conclusion}

This paper analyzed the effects of scale economies, scope economies and connection economies among group members, as well as the problems and challenges faced by knowledge sharing, including insufficient total knowledge resource amount, scarce high-quality knowledge resources, lack of external pressure and internal motivation, and shortage of incentive and restrictive mechanisms. Applying the evolutionary game model, this paper discussed the game process and strategy selection of knowledge sharing among the member schools of basic education groups, and obtained that the long-term equilibrium structure of the evolutionary game of the basic education group knowledge sharing system may be complete knowledge sharing or complete knowledge not-sharing, and this result is closely related to the payoff matrix and initial status of the evolutionary game. The influencing factors of the knowledge sharing strategy of basic education groups can be summarized as: knowledge sharing benefits, knowledge sharing risks and knowledge sharing difficulties.

Based on the above results, this paper proposed the following countermeasures: first, establish knowledge sharing systems in education groups; second, establish incentive and restrictive mechanisms for knowledge sharing in education groups; third, unclog interest demand channels of knowledge sharing in education groups; fourth, establish a mechanism for evaluating and protecting group knowledge sharing achievements; and fifth, build knowledge sharing platforms to reduce costs of knowledge transfer.

\section{Acknowledgement}

Beijing Social Science Foundation. The article is a phased research result of the project "An Empirical Study on the Influencing Factors of the Governance Performance of Basic Education Groups from the Perspective of Interne+ Based on Network Organizations" (Project code: 16JYC014). 


\section{References}

[1] Song, H. (2013). An Empirical Research on Strategic Alliances. Shanghai: Shanghai People's Publishing House.

[2] Sakulvirikitkul, P., Sintanakul, K., Srisomphan, J. (2020). The design of a learning process for promoting teamwork using project-based learning and the concept of agile software development, International Journal of Emerging Technologies in Learning, 15(3): 207-222. https://doi.org/10.3991/ijet.v15i03.10480

[3] Navimipour, N.J., Charband, Y. (2016). Knowledge Sharing Mechanisms and Techniques in Project Teams: Literature Review, Classification, and Current Trends. Computers in $\mathrm{Hu}-$ man Behavior, 62: 730-742. https://doi.org/10.1016/j.chb.2016.05.003

[4] Ali, A.A., Selvam, D.D.D.P., Paris, L., Gunasekaran, A. (2019). Key Factors Influencing Knowledge Sharing Practices and Its Relationship with Organizational Performance within the Oil and Gas Industry. Journal of Knowledge Management, 23(9): 1806-1837. https:// doi.org/10.1108/JKM-06-2018-0394

[5] Laitinen, K., Valo, M. (2018). Meanings of Communication Technology in Virtual team meetings: Framing technology-related interaction. International Journal of HumanComputer Studies, 111: 12-22. https://doi.org/10.1016/j.ijhcs.2017.10.012

[6] Maduka, N.S., Edwards, H., Greenwood, D., Osborne, A., Babatunde, S.O. (2018). Analysis of competencies for effective virtual team leadership in building successful organisations. Benchmarking: An International Journal, 25(2): 696-712. https://doi. org/10.1108/BIJ-08-2016-0124

[7] Goettsch, K.L. (2016). Working with Global Virtual Teams: A Case Study Reality Check on Intercultural Communication Best Practices. Global Advances in Business and Communica-tions Conference \& Journal, 5(3). https://commons.emich.edu/gabc/vol5/iss1/ $\underline{3}$

[8] Dong, W., Ehrlich, K., Macy, M.M., Muller, M. (2016). Embracing Cultural Diversity: Online Social Ties in Distributed Workgroups. In Proceedings of the 19th ACM Conference Computer Cooperative Work \& Social Computing-CSCW'16, New York, NY, USA, 273-286. Available online: http://dl.acm.org/citation.cfm?doid=2818048.2835198, accessed on 12 February 2020. https://doi.org/10.1145/2818048.2835198

[9] Al Zain, N.L., Vasilache, S., Incze, C.B. (2018). The Significance and Managerial Challeng-es of Virtual Teamworking. Proceedings of the International Conference on Business Excel-lence, 12(1): 25-33. https://doi.org/10.2478/picbe-2018-0004

[10] Kong, X.D., Xu, Q., Zhu, T. (2020). Dynamic Evolution of Knowledge Sharing Behavior among Enterprises in the Cluster Innovation Network Based on Evolutionary Game Theory. Sustainability, 12(1): 75. https://doi.org/10.3390/su12010075

[11] Olaisen, J., Revang, O. (2017). Working Smarter and Greener: Collaborative Knowledge Sharing in Virtual Global Project Teams. International Journal of Information Management, 37(1): 1441-1448. https://doi.org/10.1016/j.ijinfomgt.2016.10.002

[12] Lekhawipat, W., Wei, Y.H., Lin, C. (2018). How Internal Attributions Affect Knowledge Sharing Behavior. Journal of Knowledge Management, 22(4): 867-886. https://doi.org/ 10.1108/JKM-02-2017-0081

[13] Wu, W. L., Lee, Y.C. (2016). How to Make a Knowledge-sharing Group: A Group Social Capital Perspective. Personnel Review, 45(3): 523-538. https://doi.org/10.1108/PR-122013-0227

[14] Moser, C., Deichmann, D. (2020). Knowledge Sharing in Two Cultures: The Moderating Effect of National Culture on Perceived Knowledge Quality in Online Communities. Euro- 
pean Journal of Information Systems, 1-19. https://doi.org/10.1080/0960085X.2020.1817 $\underline{802}$

[15] Wang, C.F., Hu, Q.Y. (2020). Knowledge Sharing in Supply Chain Networks: Effects of Collaborative Innovation Activities and Capability on Innovation Performance. Technovation, 94-95: 102010. https://doi.org/10.1016/j.technovation.2017.12.002

[16] Evers, G., Chappin, M.M.H. (2020). Knowledge sharing in smart grid pilot projects. Energy Policy, 143: 111577. https://doi.org/10.1016/j.enpol.2020.111577

[17] Ali, A.A., Selvam, D.D.D.P., Paris, L., Gunasekaran, A. (2019). Key Factors Influencing Knowledge Sharing Practices and Its Relationship with Organizational Performance within The Oil and Gas Industry. Journal of Knowledge Management, 23(9): 1806-1837. https:// doi.org/10.1108/JKM-06-2018-0394

[18] Lee, J.Y., Yang, Y.S., Park, B.I. (2020). Interplay between Dual Dimensions of Knowledge Sharing within Globalized Chaebols: The Moderating Effects of Organization Size and Global Environmental Munificence. International Business Review, 29(6): 101637. https://doi.org/10.1016/j.ibusrev.2019.101637

[19] Kang, J., Lee, J.Y. (2017). Performance effects of explorative and exploitative knowledge sharing within korean chaebol MNEs in China. International Journal of Technology Management, 74(4): 70-95. https://doi.org/10.1504/IJTM.2017.10004271

[20] Lee, J.Y., Jang, S.H., Lee, S.Y. (2018). Paternalistic leadership and knowledge sharing with outsiders in emerging economies: Based on social exchange relations within the china con-text. Personnel Review, 47(5): 1094-1115. https://doi.org/10.1108/PR-03-2017-0068

[21] Li, X.Q., Roberts, J., Yan, Y., Tan, H. (2016). Management of cultural differences under various forms of China-UK higher education strategic alliances. Studies in Higher Education, 41(4): 774-798. https://doi.org/10.1080/03075079.2014.966664

[22] Ren, Z.A. (2005). Knowledge sharing and economies of scale, economies of scope, and economics of connection. Science of Science and Management of S.\&T., 10: 119-124. https://doi.org/10.3969/j.issn.1002-0241.2005.10.025

[23] Corporan, R.A., Joo-Nagata, J., Martín García, A.V., Martín, A.H. (2020). Perception of teachers on collaborative tools knowledge level mediated by ict and their experience with students, International Journal of Emerging Technologies in Learning, 15(11): 137-161, https://doi.org/10.3991/IJET.V15I11.13121

[24] Jorgen W. (2015). Weibull. Evolutionary game theory. Shanghai: Shanghai People's Publishing House (Sweden).

[25] Liu, C. (2010). Knowledge collaboration and sharing model of enterprise strategic alliances. Science and Technology Management Research, 5: 102-105. https://doi.org/10.39 69/j.issn.1000-7695.2010.05.035

[26] Xi, L., Peng, C. (2006). Influencing factors and countermeasures of inter-organizational knowledge transfer in strategic alliances. Science and Technology Management Research, 3: 166-169. https://doi.org/0.3969/j.issn.1000-7695.2006.03.053.

[27] Zhao, Q. (2014). Game analysis of compulsory education resource sharing. Educational Development Research, 6: 35-39. https://doi.org/CNKI:SUN:SHGJ.0.2014-06-010.

[28] Yang, Z. (2019). Operation mechanism of vocational education groups based on benefit coordination. Big Vision, 5: 39-43.

[29] Zhu, N.B., Luo, S.Q. (2019). Game equilibrium and incentive and restrictive mechanism of resource allocation in education groups. Education Theory and Practice, 19: 25-28. 


\section{Author}

Yafei Wang, female, PhD student at Capital Normal University; lecturer at North China University of Technology (NCUT), School of Humanities and Law; research direction: education group development and education technology application; mailing address: School of Humanities and Law, North China University, Shijingshan District, Beijing, China (post code 100144), Email: faye791108@163.com.

Article submitted 2020-12-12. Resubmitted 2021-01-23. Final acceptance 2021-01-28. Final version published as submitted by the authors. 